\title{
Photocatalytic Activity of Nanostructured Titanium Dioxide Thin Films
}

\author{
Zdenek Michalcik, ${ }^{1,2}$ Marta Horakova, ${ }^{1}$ Petr Spatenka, ${ }^{1,2}$ \\ Sarka Klementova, ${ }^{3}$ Martin Zlamal, ${ }^{4}$ and Nicolas Martin ${ }^{5}$ \\ ${ }^{1}$ Department of Material Science, Faculty of Mechanical Engineering, Technical University of Liberec, Studentska 2, \\ 46117 Liberec, Czech Republic \\ ${ }^{2}$ Department of Applied Physics and Technology, University of South Bohemia, Jeronymova 10, 37001 Ceske Budejovice, Czech Republic \\ ${ }^{3}$ Faculty of Science, University of South Bohemia, Branisovska 31, 37005 Ceske Budejovice, Czech Republic \\ ${ }^{4}$ Department of Inorganic Technology, VSCHT, Technická 5, Prague 6, 166 28, Dejvice, Czech Republic \\ ${ }^{5}$ Département MN2S, Institut FEMTO-ST (UMR 6174) CNRS, UFC ENSMM UTBM, 26 Chemin de l'Épitaphe, \\ 25030 Besançon Cedex, France
}

Correspondence should be addressed to Zdenek Michalcik, zdenek.michalcik@gmail.com

Received 29 April 2012; Revised 17 June 2012; Accepted 1 July 2012

Academic Editor: Panagiotis Lianos

Copyright ( 2012 Zdenek Michalcik et al. This is an open access article distributed under the Creative Commons Attribution License, which permits unrestricted use, distribution, and reproduction in any medium, provided the original work is properly cited.

\begin{abstract}
The aim of this paper is to investigate the properties and photocatalytic activity of nanostructured $\mathrm{TiO}_{2}$ layers. The glancing angle deposition method with DC sputtering at low temperature was applied for deposition of the layers with various columnar structures. The thin-film structure and surface morphology were analyzed by XRD, SEM, and AFM analyses. The photocatalytic activity of the films was determined by the rate constant of the decomposition of the Acid Orange 7. In dependence on the glancing angle deposition parameters, three types of columnar structures were obtained. The films feature anatase/rutile and/or amorphous structures depending on the film architecture and deposition method. All the films give the evidence of the photocatalytic activity, even those without proved anatase or rutile structure presence. The impact of columnar boundary in perspective of the photocatalytic activity of nanostructured $\mathrm{TiO}_{2}$ layers was discussed as the possible factor supporting the photocatalytic activity.
\end{abstract}

\section{Introduction}

Titanium dioxide is one of the most investigated materials in the last decades. Three forms of $\mathrm{TiO}_{2}$ can be found in nature: anatase, rutile, and brookite. Its properties like a high refractive index, chemical and mechanical stability, and/or photocatalytic activity [1-3] predetermine this material for a wide range of applications.

One of the most attractive areas concerning titanium dioxide is its photocatalytic activity. The photocatalytic effect of $\mathrm{TiO}_{2}$ material is based on generation of electron-hole pairs due to the UV irradiation of $\mathrm{TiO}_{2}$. The generated pairs diffuse to the surface of the material and participate in the surface reaction leading to the decomposition of adsorbed matter [2].
A lot of articles have been published about the relation between the thin-film structure and the photocatalytic activity [4-6]. Generally, the presence of anatase or its mixture with rutile has been reported as an assumption for the photocatalytic activity of titanium dioxide films. The rutile acts as an antenna extending the photoactivity into visible wavelengths, and the structural arrangement of the similarly sized $\mathrm{TiO}_{2}$ crystallites creates catalytic "hot spots" at the rutile-anatase interface [7-10].

One of the most important factors affecting the photocatalytic efficiency is the lifetime of the electron/hole pairs. The excitons generated during the UV irradiation of $\mathrm{TiO}_{2}$ layers dissipate the stored energy within few nanoseconds by the recombination. Doping of the thin-film surface leads to enhancement of the excitons lifetime (as 
well as photocatalytic activity) because of a Schottky's barrier creation $[11,12]$. Similarly, the existence of the grain boundary in $\mathrm{TiO}_{2}$ material also enhances the photocatalytic reaction [13]. The explanation of this effect is related to bending of energetic bands. The bent bands around grain boundaries tend to separate the electrons and holes resulting in enhancement their lifetimes.

$\mathrm{TiO}_{2}$ photocatalytic films can be prepared by various methods of which SOL-GEL, PECVD, and/or PVD belong to the most frequently used. One of the well-available PVD technologies enabling the deposition of thin films with columnar structure is the so-called glancing angle deposition. (GLAD) [14-16]. This method is based on variation of the incident particle angle to the substrate as schematically shown in Figure 1. The variation of the incident angle enables formation of nanostructured films with oriented columnar structures.

The presence of columnar structure and architecture type of columns strongly affect functional properties of thin films [18-20]. The aim of our investigations was to study the impact of an oriented structure on the photocatalytic activity $\mathrm{TiO}_{2}$ layers.

\section{Experimental Section}

$\mathrm{TiO}_{2}$ films were deposited in a classical PVD apparatus equipped with a movable substrate nonheatable holder. Changing the angle of the holder and/or its rotation enables the control of the film columnar structure. The detailed description of the experimental setup has been described elsewhere [14].

The ultimate pressure inside the chamber was about $1 \mathrm{~Pa}$; typical values of discharge current and voltage were $200 \mathrm{~mA}$ and $450 \mathrm{~V}$, respectively. Argon with the admixture of oxygen was used as a working gas mixture. The oxygen was flowed either constantly of $2 \mathrm{sccm}$ (reactive gas constant flowRGCF) or in a pulsed mode (reactive gas pulsing processRGPP). The period of the pulsation was $45 \mathrm{~s}$ with the $t_{\mathrm{on}}=$ $27 \mathrm{~s}$ and $t_{\text {off }}=18 \mathrm{~s}$.

The amount of the injected oxygen during the $t_{\mathrm{on}}$ of RGPP was two times higher than the amount of the constantly injected oxygen into the chamber during RGCF. The reason for this was to reach the same stoichiometry of the layers- $-\mathrm{TiO}_{2}$. The same stoichiometry of deposited layers was proved by ESCA analysis.

The surface morphology of thin films was investigated by the atomic force microscopy (AFM) and scanning electron microscopy (SEM). Nanoscope 3 MORTIMORT machine was used for the AFM. Surfaces of all the samples were scanned by the contactless regime using the FastScan method with resonation frequency $50 \mathrm{kHz}$. The software Gwyddion was used for the evaluation of the arithmetic roughness calculation. The values of the arithmetic roughness were evaluated due to the comparison of AFM data matrix by the middle plane interlay. The values of the arithmetic roughness indicate the arithmetic deviation from a mean value of point heights.

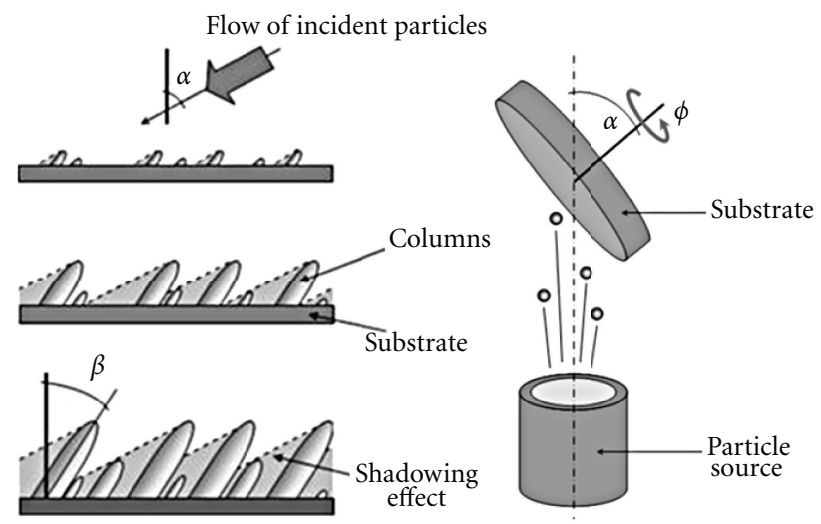

FIGURE 1: Principles of glancing angle deposition [17].

The JEOL-JSM 740 scanning electron microscope operated with accelerating potential $5 \mathrm{kV}$ and working distance of $14.4 \mathrm{~mm}$.

The thin-film structure was investigated by the X-ray diffraction. Due to a low value of the thin-film thickness, the special diffractometer X'Pert Pro made by the PANalytical company was used with $\operatorname{CoK} \beta$. The Göbel mirror was placed into the way of an incident beam. The angle of the beam incidence was $3^{\circ}$.

For the determination of the ratio of specific surface $P$ to nominate surface $P_{0}$ the method based on the sorption of krypton was performed. Sorption measurements of porous thin films were carried out at the temperature of $77 \mathrm{~K}$. Micromeritics ASAP 2010 was used for the Krypton volume adsorption measurements. The $P / P_{0}$ ratio was calculated from the measured lines using the basis of BET analysis. The method is described in detail in [21].

The photocatalytic activity was derived from the decomposition speed of aqueous solution of the Orange 7 (sodium salt of sulphonated azo dye), assuming the LangmuirHinshelwood law for degradation according to the pseudofirst-kinetic order. The experimental method and determination of the apparent kinetic constant Kare in full details described in paper [22]. This kinetic constant $K$ was normalized to the UV irradiation intensity $\left(\mathrm{W} / \mathrm{m}^{2}\right)$, the volume of AO7 solution $\left(\mathrm{m}^{3}\right)$, and the area of irradiated $\mathrm{TiO}_{2}$ layer $\left(\mathrm{m}^{2}\right)$.

The photocatalytic activity of the deposited films was also compared with the films prepared from commercially available Evonik/Degussa Aeroxide P25 photocatalyst. Samples in form of this powder were prepared by sedimentation on soda lime glass substrates. The sedimentation was performed by placing $0.2 \mathrm{~mL} / \mathrm{cm}^{2}$ of aqueous suspension of known catalyst concentration on the substrate, followed by drying. After the drying process under laboratory condition, the deposited layers were heated to $300^{\circ} \mathrm{C}$ for 30 minutes to achieve the better adhesion of the particulate layer on the glass support. Such prepared layers contain $0.5 \mathrm{mg}$ of P25 per $\mathrm{cm}^{2}$, with layer thickness of 5 microns. The efficiency of Degussa Aeroxide P25 is shown only for the comparison of $\mathrm{TiO}_{2}$ films made by PVD GAD with highly efficient photocatalyst. 


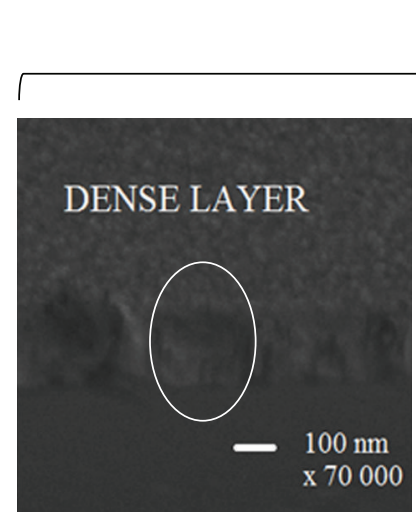

(a)

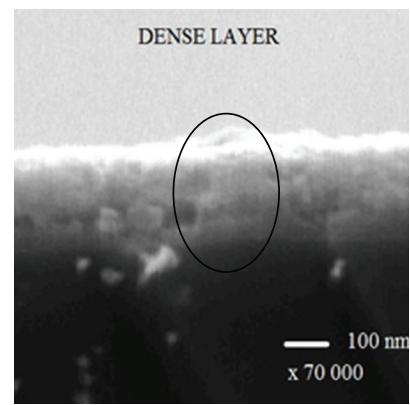

(e)

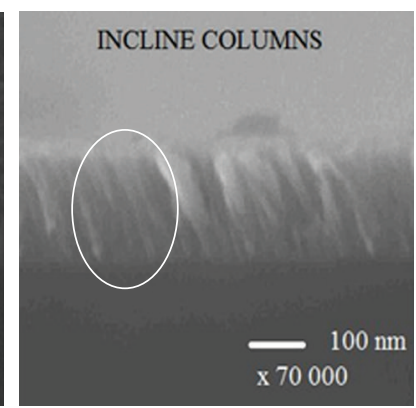

(b)

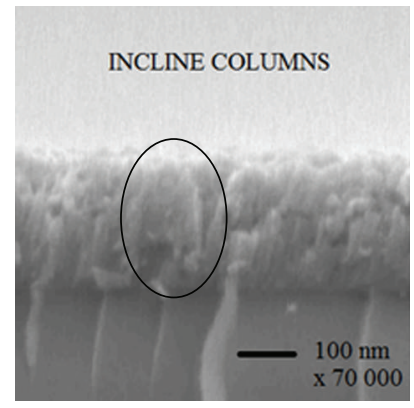

(f)

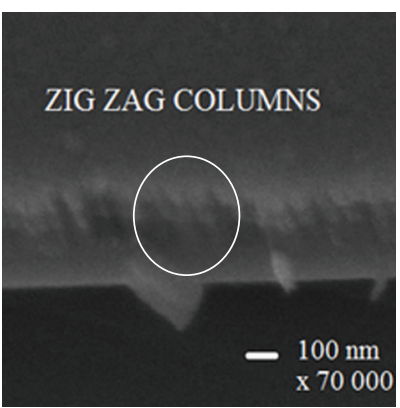

(c)

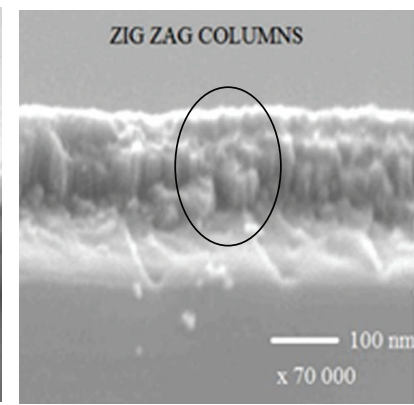

(g)

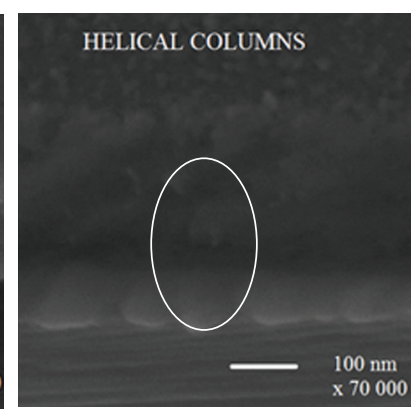

(d)

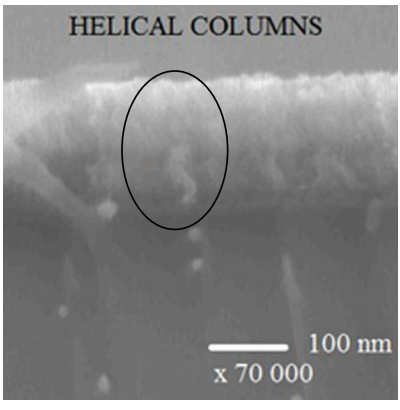

(h)

RGPP

FIGURE 2: SEM analyses of chosen thin-film edges.

\section{Results and Discussion}

Four types of the thin-film structure were prepared in dependency on GLAD parameters (a deposition angle $\alpha$ and rotation angle $\Phi$; see Figure 10) — dense layer and three columnar structured types of the thin films: incline, zigzag and helical columns (see Figure 10).

Both the RGCF and RGPP methods were applied for deposition of each type of the structure, presented in Figure 10 . The thickness of all the layers was approximately $200 \mathrm{~nm}$. The SEM pictures of edge fracture are presented in Figure 2.

The thin films called dense layers (Figures 2(a) and 2(e)) were deposited with the substrate placed perpendicularly to the particle flow (parallel to the target-the most frequently used method for PVD) and without any substrate rotation. The results of the SEM analysis for this type of the deposition are in a good agreement with Thornton's thin-film growth model defining so-called T-zone [23]. This zone is typical for its dense and fiber-like grain, in which the grain outlines are difficult to identify, which can be seen in Figures 2(a) and 2(e) (see circles). The layers called incline (Figures 2(b) and 2(f)), zigzag (Figures 2(c) and 2(g)), and helical columns (Figures 2(d) and 2(h)) clearly show the columnar structure corresponding to the glancing angle deposition parameters. The individual columns are in the mutual contact, so the hypothesis of the columnar boundary presence is proved by this analysis.
The surface morphology was investigated by SEM and AFM analysis. The SEM pictures of surfaces of particular samples are shown in Figure 3.

The surface of dense layers (both RGCF and RGPP: Figures 3(a) and $3(\mathrm{e})$ ) proved the smoothest surface in comparison to the oriented structured thin films (incline/zigzag/helical columns). Dense layers (both RGCF and RGPP) are typical for the absence of a global shape formation (see Figures 3(a) and 3(e)) which can be seen on the surfaces of the rest of the analyzed samples (see Figures 3(b), $3(\mathrm{c}), 3(\mathrm{~d}), 3(\mathrm{f}), 3(\mathrm{~g})$, and $3(\mathrm{~h}))$. For both deposition methods, thin films with incline columnar structure proved the presence of a global shape formation with diameter in the limits between $20 \mathrm{~nm}$ and $60 \mathrm{~nm}$ (see Figures 3(b) and 3(f)). The layer with zigzag columnar structure made by RGCF showed smooth surface with poor presence of a global shape formation with diameter in the limits $10 \mathrm{~nm}$ and $30 \mathrm{~nm}$ (see Figure 3(c)), whilst the same structured thin film made by RGPP proved the rich presence of such grain formation with diameter up to $100 \mathrm{~nm}$ (see Figure $3(\mathrm{~g})$ ). From the point of view of deposition method, similar results in surface differences were observed for thin films with helical-column structure. The layer made by RGCF showed the presence of a global shape formation with diameter approximately $20 \mathrm{~nm}$ (see Figure 3(d)) whilst the layer made by RGPP proved the rich presence of grains with diameter in the limits $50 \mathrm{~nm}$ and $100 \mathrm{~nm}$ (see Figure 3(h)). Figure 3 demonstrates that that layers made by RGPP proved evidently more diverse 


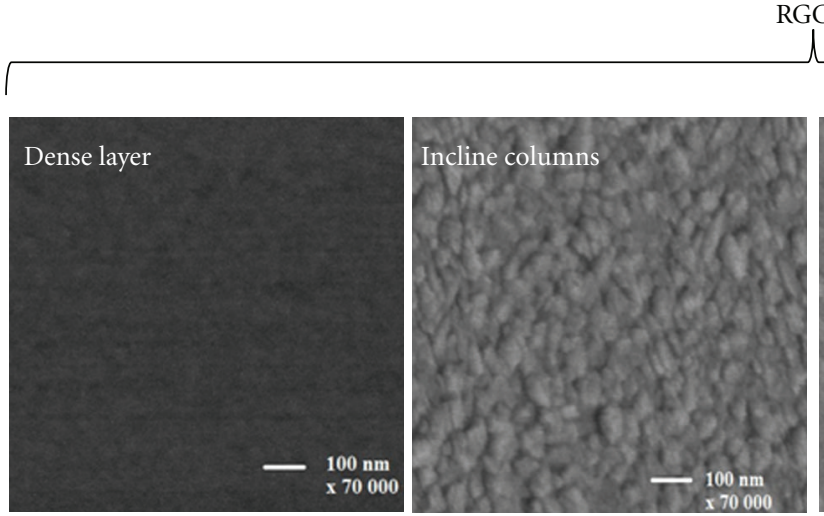

(a)

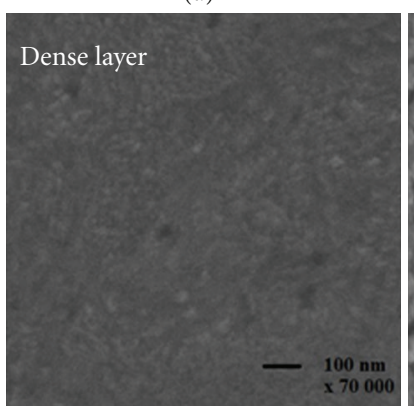

(e) (b)

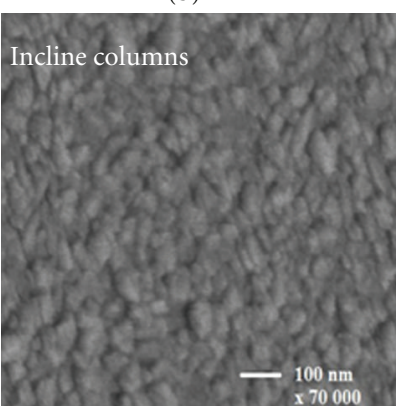

(f)

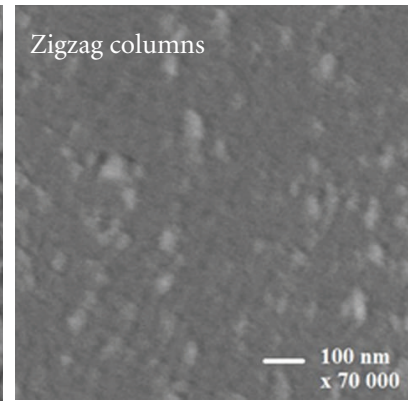

(c)

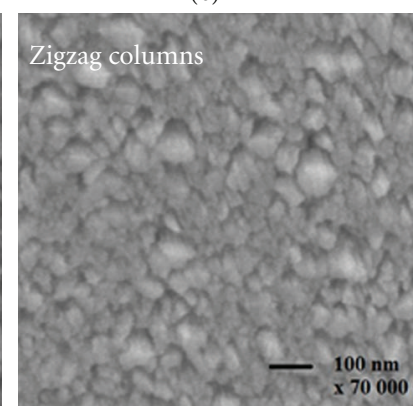

(g)

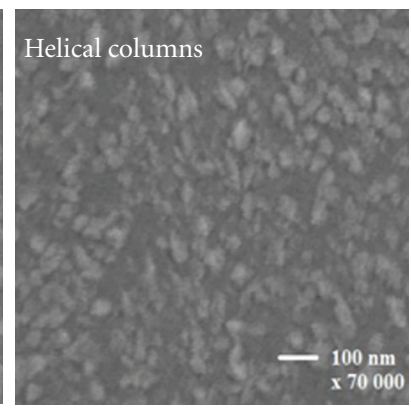

(d)

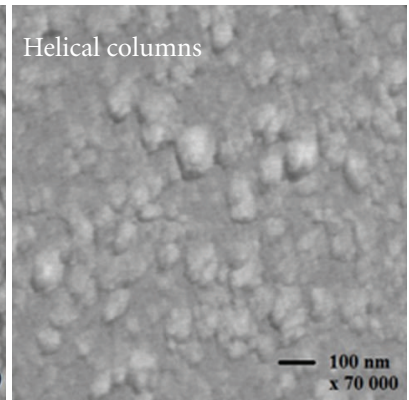

(h)

RGPP

FIgURE 3: SEM surface photos.

structure of surfaces in comparison to the surfaces of the thin films made by RGCF.

To quantify the differences in the thin-film surface structure, the arithmetic roughness measurement by AFM was evaluated and the arithmetic roughness for was calculated for all the samples. Results are summarized in Figure 4. Each value represents average value of 5 independent measurements.

The lowest value of the arithmetic roughness was observed at the dense layer made by RGCF-1.6 nanometers. The layer with zigzag columns made by RGPP showed the highest value of the arithmetic roughness-3.9 nanometers. Higher values of the arithmetic roughness observed at the layers with the oriented structure (incline, zigzag, and helical columns) are clearly visible in comparison with the nonoriented structured layers (dense layers). This is in a good agreement with the SEM surface analysis shown in Figure 3, where the dense layers proved the smoothest surface in comparison to the oriented structure layer.

The pulsation of the reactive gas is known to reduce the target poisoning resulting in higher sputtering yield. The higher deposition rate during the RGPP in combination with moderate sputtering of the substrate during the oxygen off-phase might be the reason of generally higher surface roughness of samples prepared by RGPP in comparison with those deposited by RGCF.

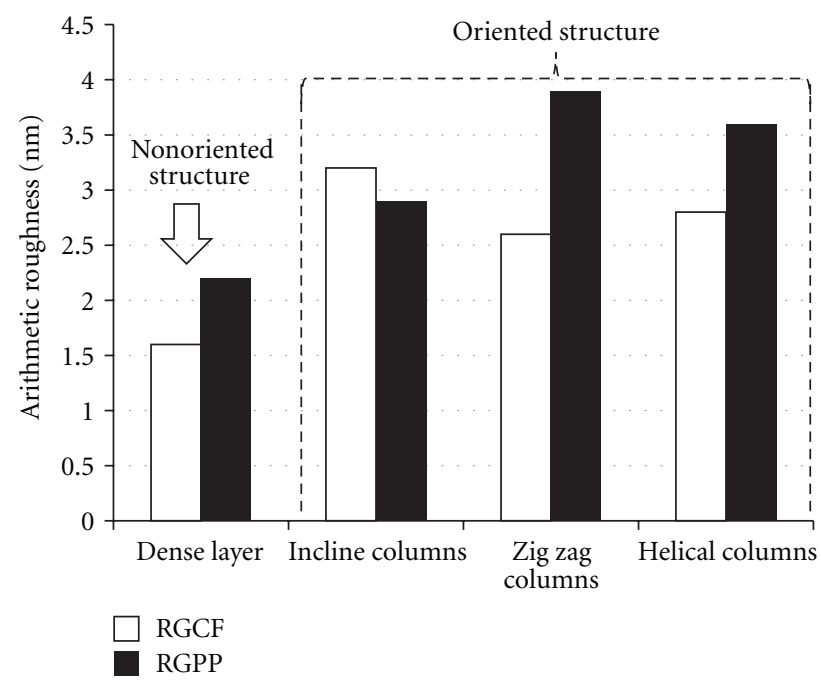

FIGURE 4: Roughness in dependency on layers structure.

High specific surface is a general assumption for effective catalytic reaction. Jong [24] reported the increased photocatalytic activity with larger specific surface of titanium dioxide thin films. The specific surface was determined by the krypton sorption method on selected samples. An example 


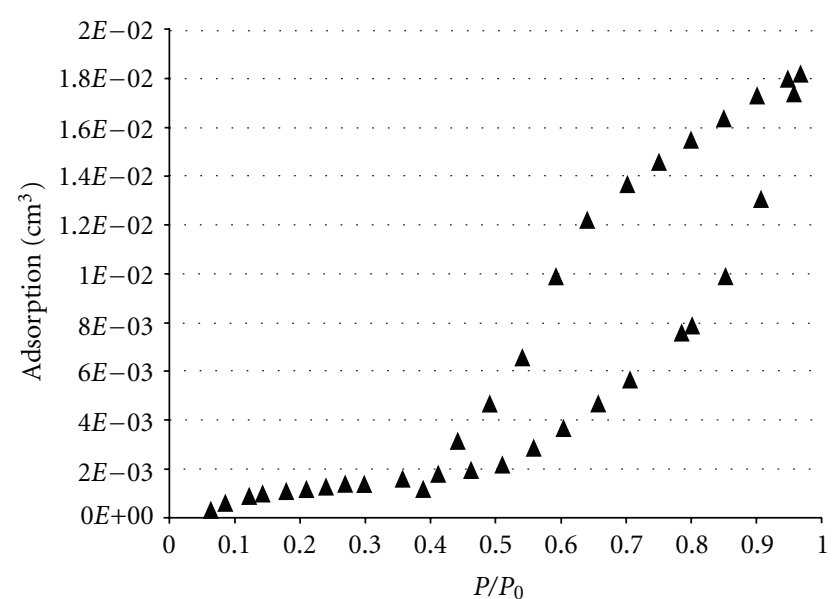

A Points showing the dependency of adsorption on relative pressure

FIGURE 5: Dependency of adsorption on relative pressure during $\mathrm{Kr}$ adsorption.

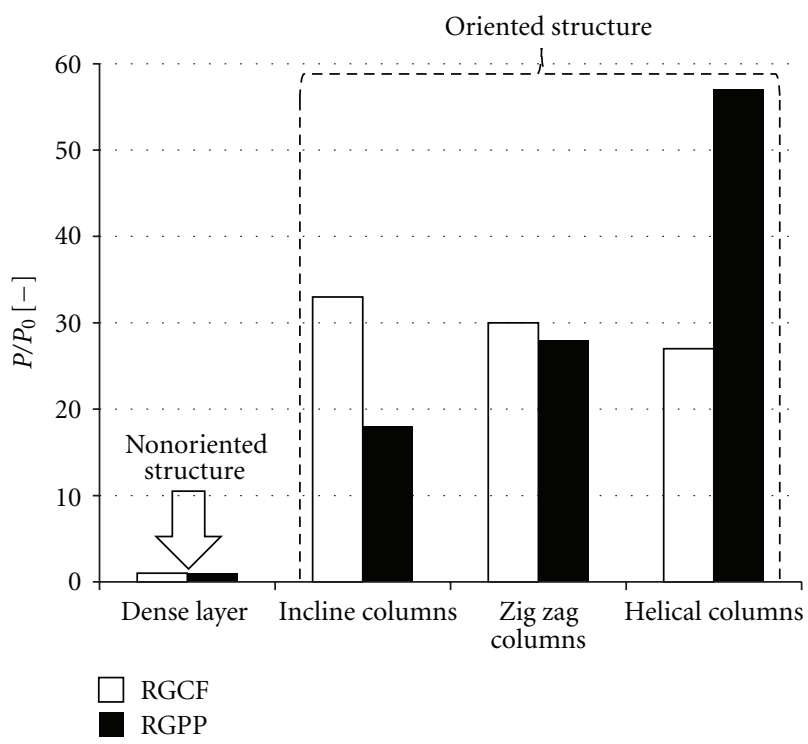

FIgure 6: Specific surfaces of $\mathrm{TiO}_{2}$ layers.

of a typical measured absorption curve is in Figure 5. The quantitative values of the specific surfaces $P$ normalized to the nominated surface $P_{0}$ are summarized in Figure 6.

The normalized specific surface $P / P_{0}$ of the films with oriented structure is substantially higher than the $P / P_{0}$ of the non/structured films. The layers with the oriented structure proved also higher arithmetic roughness in comparison with nonoriented thin films. The most probable explanation of these results is based on the hypothesis that columnar structure enhances the pores forming which could positively affect the sorption, and so the high values of $P / P_{0}$ could be observed at the thin films with oriented structure, especially the most pronounced for the layer with helical type of columns deposited by RGPP. This layer has 60 times higher value of $P / P_{0}$ ratio than the dense layers.

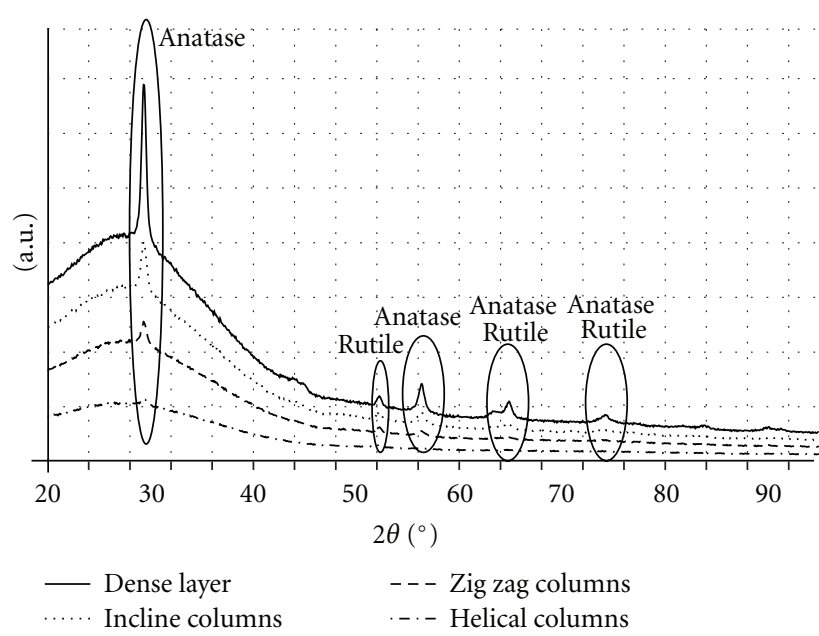

FIgURE 7: Results of low-angle XRD for layers made by RGCF.

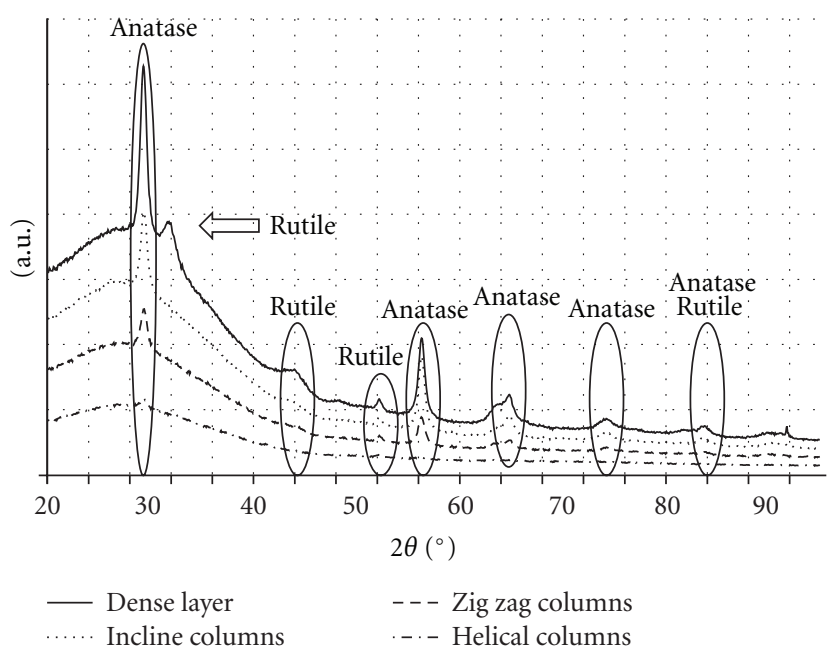

FIgURE 8: Results of low-angle XRD for layers made by RGPP.

To the investigation of crystalline quality, low-angle $\mathrm{X}$-ray diffraction analysis was realized on the individual representatives for each type of the structure and both deposition methods. In Figure 7 results of this investigation are shown for layers made by RGCF; in Figure $8 \mathrm{X}$-ray diffraction results are shown for RGPP deposition method.

It is obvious from Figures 7 and 8 that layers with the helical structure (both RGCF and RGPP) seem to be amorphous (exactly the crystalline formation is below the resolution limit of the used method which is $3 \mathrm{~nm}$ ).

Mostly the presence of the anatase structure (angle values-29.9 $, 57.3^{\circ}, 74.9^{\circ}$ ) was proved by the low-angle XRD for incline and zigzag column architecture type (both RGCF and RGPP), especially anatase peaks relevant to the angle $29.9^{\circ}$. Rutile phase is proved by the peak with low intensity at the angle value equal to $51.6^{\circ}$.

The normalized kinetic constants $r$ in dependency on the layer structure are presented in Figure 9. The kinetic constant $r$ for Aeroxide $\mathrm{TiO}_{2}$ P25 Degussa layer (with thickness approximately $5 \mu \mathrm{m}$ ) is also displayed. 


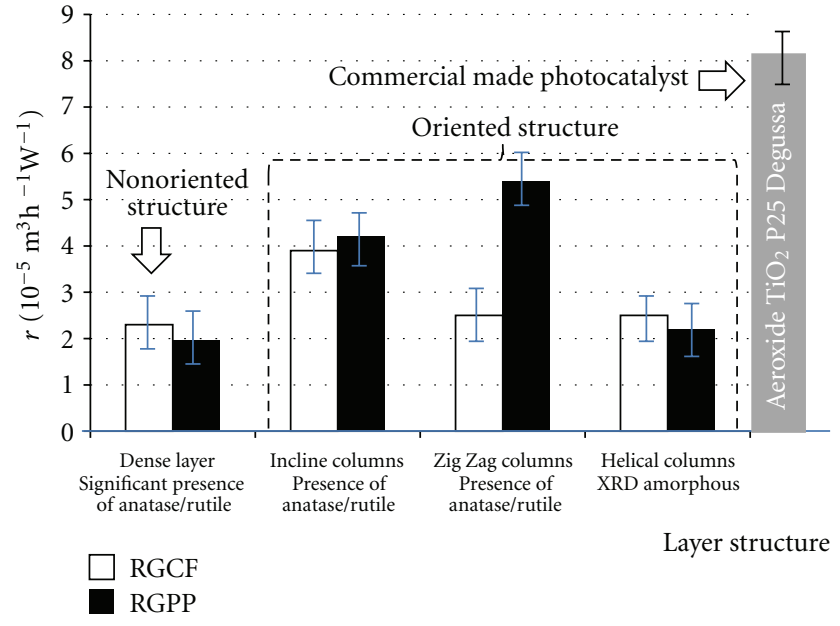

Figure 9: Photocatalytic activities in dependency on thin-film structure.

The dark absorption measurement was part of the photocatalytic activity analysis. All tested samples were immersed in the AO7 solution in the dark for 6 hours. The AO7 concentration changes were evaluated due to UV/VIS spectroscopy, and no differences between the initial and final concentration were observed, even for films with different values of the specific surface area (Aeroxide $\mathrm{TiO}_{2} \quad \mathrm{P} 25$ Degussa). Based on these results, the contribution of dark absorption to the $\mathrm{AO} 7$ concentration decrease was excluded.

All tested samples were irradiated by UV for the same time of 6 hours and only the initial and final concentrations were analyzed. According to our experiences with this type of experiments and results presented in [25-27], the dependence of $\mathrm{AO} 7$ decomposition on the time of irradiation has a decreasing exponential character.

Figure 9 summarized the obtained reaction constants. All the samples evidence photocatalytic activity in the limits between $2 \cdot 10^{-5} \mathrm{~m}^{3} \mathrm{~h}^{-1} \mathrm{~W}^{-1}$ and $5.4 \cdot 10^{-5} \mathrm{~m}^{3} \mathrm{~h}^{-1} \mathrm{~W}^{-1}$. The highest value of $r$ was reached with the incline-columned layers reaching up to $70 \%$ of Aeroxide $\mathrm{TiO}_{2}$ P25 Degussa efficiency.

As mentioned above, the photocatalytic activity is connected with presence of anatase or anatase/rutile crystalline fractions (Figures 7 and 8). The peaks with highest intensity relevant for both the anatase and rutile were found for the dense layers. Thus these films, in comparison with the other layers, contain anatase/rutile crystalline structure. However, these layers evidence the lowest photocatalytic activity of all the investigated samples.

On the other hand, the films with helical-columns structure evidence substantial photoactivity eventhough they did not prove any crystalline phases. The dense layers should exceed the photocatalytic activity of the thin films with helical-column structure due to the positive impact of the crystalline anatase/rutile phases [28-30]. However, from Figure 9 the comparable values are obvious, both for the dense- and oriented-structured layers.
The high value of the specific surface area connected to the layer with helical columns made by RGPP should be one of the factors explaining the comparable photocatalytic activity of amorphous helical-column layers with dense layers proving the presence of anatase and rutile. On the other hand, from Figure 6 it is obvious that the specific surface area of the layer with the helical columns made by RGCF is approximately two times lower than the layer with the helical columns made by RGPP. However the layer made by RGCF proved a higher photocatalytic activity than the layer deposited by RGPP (Figure 9). The value of ratio $P / P_{0}$ for zigzag column layer made by RGPP is almost two times lower than that for the layer with helical columns made by RGPP, but the photocatalytic activity of zigzag layer is more than two times higher. Thus the factor of the specific surface area could not unambiguously explain the high photocatalytic activity of the nanostructured films.

As already mentioned above, the photocatalytic effect of the $\mathrm{TiO}_{2}$ is connected with anatase/rutile structure and amorphous phase is swallowed to be detrimental in pure $\mathrm{TiO}_{2}$ photocatalyst. On the other hand Horakova et al. [11] have found that incorporation of $\mathrm{Ag}$ nanoparticles into the bulk of amorphous $\mathrm{TiO}_{2}$ film also results in substantial enhancement of their photocatalytic activity. Enhancement of the photocatalytic efficiency due to the formation of metal nanoparticles on the surface of photocatalytic anatase films was proved by several authors $[2,22]$. These particles form a metal/semiconductor junction acting as an electron trap resulting in the life-time enhancement of the electronhole pairs. Kamei [13] reported direct observation of grainboundary effect on the photocatalytic activity of bicrystalline rutile $\mathrm{TiO}_{2}$. This article proved that the existence of the grain boundary in $\mathrm{TiO}_{2}$ crystal enhanced the photocatalytic reactions. The authors of that article assumed that around the boundary the bending of band gaps is realized, leading to the enhancement of the electron-hole life-time due to the electron capture. Thus presence of some kind of boundary (Schotky's barrier - metal/semiconductor boundary; crystalline phases/amorphous phases boundary; grain boundary) results in the improvement of the $\mathrm{TiO}_{2}$ photocatalytic activity. We believe that the columnar structure formation (in fact the boundary formation due to the mutual contact of individual columns) is one of the factors leading to the observed photocatalytic efficiency of the amorphous nanostructured films due to enhancement of the electron-hole pairs (excitons) lifetime due to the electron-hole separation on the columnar boundary of the oriented structured layers.

\section{Conclusion}

$\mathrm{TiO}_{2}$ thin films were prepared by the GLAD PVD method. The films evidenced nanostructured columnar structure. They are characterized by higher surface roughness and substantial higher specific surface in comparison with films prepared by conventional PVD. All the films evidence photocatalytic activity even those with amorphous character. Boundaries between the oriented structures are explained to be a reason of the photocatalytic activity of amorphous $\mathrm{TiO}_{2}$ 


\begin{tabular}{|c|c|c|}
\hline $\begin{array}{c}\text { Type of } \\
\text { architecture }\end{array}$ & Normal angle $\alpha\left(^{\circ}\right)$ & Rotation angle $\Phi$ \\
\hline Dense layer & 0 & No rotation during the deposition \\
\hline Incline & 80 & $\begin{array}{c}\text { No rotation during the deposition } \\
\text { Rotation } 180^{\circ} \text { in the plane of the } \\
\text { substrate every } 30 \text { minutes }\end{array}$ \\
\hline Zig zag columns & 80 & $\begin{array}{c}\text { Rotation } 90^{\circ} \text { in the plane of the } \\
\text { substrate every } 15 \text { minutes }\end{array}$ \\
\hline Helical columns
\end{tabular}

FIGURE 10: GLAD parameters relevant to specific structure.

layers. The photocatalytic activity was observed at the thin film with zigzag columnar structure made by RGPP reaching $70 \%$ efficiency of Aeroxide $\mathrm{TiO}_{2}$ P25 Degussa.

\section{Acknowledgments}

This work was supported by MSMT, Project NANOPIN 1M0577, by GA AV CR, Project No. KAN101120701, and by the project CZ.1.05/2.1.00/03.0086 funded by European Regional Development Fund.

\section{References}

[1] M. K. Seery, R. George, P. Floris, and S. C. Pillai, "Silver doped titanium dioxide nanomaterials for enhanced visible light photocatalysis," Journal of Photochemistry and Photobiology A, vol. 189, no. 2-3, pp. 258-263, 2007.

[2] A. L. Linsebigler, G. Lu, and J. T. Yates, "Photocatalysis on $\mathrm{TiO}_{2}$ surfaces: principles, mechanisms, and selected results," Chemical Reviews, vol. 95, no. 3, pp. 735-758, 1995.

[3] S. W. Ryu, E. J. Kim, S. K. Ko, and S. H. Hahn, "Effect of calcination on the structural and optical properties of $\mathrm{M} / \mathrm{TiO}_{2}$ thin films by RF magnetron co-sputtering," Materials Letters, vol. 58 , no. 5, pp. 582-587, 2004.

[4] U. Diebold, "The surface science of titanium dioxide," Surface Science Reports, vol. 48, no. 5-8, pp. 53-229, 2003.

[5] T. Watanabe, A. Nakajima, R. Wang et al., "Photocatalytic activity and photoinduced hydrophilicity of titanium dioxide coated glass," Thin Solid Films, vol. 351, no. 1-2, pp. 260-263, 1999.

[6] T. S. Yang, C. B. Shiu, and M. S. Wong, "Structure and hydrophilicity of titanium oxide films prepared by electron beam evaporation," Surface Science, vol. 548, no. 1-3, pp. 75-82, 2004.

[7] A. Sclafani and J. M. Herrmann, "Comparison of the photoelectronic and photocatalytic activities of various anatase and rutile forms of titania in pure liquid organic phases and in aqueous solutions," Journal of Physical Chemistry B, vol. 100, no. 32, pp. 13655-13661, 1996.

[8] D. C. Hurum, A. G. Agrios, K. A. Gray, T. Rajh, and M. C. Thurnauer, "Explaining the enhanced photocatalytic activity of Degussa P25 mixed-phase $\mathrm{TiO}_{2}$ using EPR," Journal of Physical Chemistry B, vol. 107, no. 19, pp. 4545-4549, 2003.

[9] B. Ohtani, Y. Ogawa, and S. I. Nishimoto, "Photocatalytic activity of amorphous-anatase mixture of titanium(IV) oxide particles suspended in aqueous solutions," Journal of Physical Chemistry B, vol. 101, no. 19, pp. 3746-3752, 1997.

[10] M. F. Brunella, M. V. Diamanti, M. P. Pedeferri, F. D. Fonzo, C. S. Casari, and A. L. Bassi, "Photocatalytic behavior of different titanium dioxide layers," Thin Solid Films, vol. 515, no. 16, pp. 6309-6313, 2007.

[11] M. Horakova, N. Martin, E. Aubry, and P. Spatenka, "Photocatalysis of Ag doped $\mathrm{TiO}_{x}$ films prepared at room temperature," Catalysis Letters, vol. 132, no. 1-2, pp. 244-247, 2009.

[12] J. W. Yoon, T. Sasaki, N. Koshizaki, and E. Traversa, "Preparation and characterization of $\mathrm{M} / \mathrm{TiO}_{2}(\mathrm{M}=\mathrm{Ag}, \mathrm{Au}, \mathrm{Pt})$ nanocomposite thin films," Scripta Materialia, vol. 44, no. 8-9, pp. 1865-1868, 2001.

[13] M. Kamei, "Localization of the photocatalytic reaction on the grain boundary of bicrystalline $\mathrm{TiO}_{2}$," Applied Physics Express, vol. 1, pp. 1-3, 2008.

[14] N. Martin, J. Lintymer, J. Gavoille et al., "Reactive sputtering of $\mathrm{TiO}_{x} \mathrm{~N}_{y}$ coatings by the reactive gas pulsing process. Part I: pattern and period of pulses," Surface \& Coatings Technology, vol. 201, no. 18, pp. 7720-7726, 2007.

[15] N. Martin, J. Lintymer, J. Gavoille et al., "Reactive sputtering of $\mathrm{TiO}_{x} \mathrm{~N}_{y}$ coatings by the reactive gas pulsing process. Part II: the role of the duty cycle," Surface \& Coatings Technology, vol. 201, no. 18, pp. 7727-7732, 2007.

[16] N. Martin, J. Lintymer, J. Gavoille et al., "Reactive sputtering of $\mathrm{TiO}_{x} \mathrm{~N}_{y}$ coatings by the reactive gas pulsing process: part III: the particular case of exponential pulses," Surface \& Coatings Technology, vol. 201, no. 18, pp. 7733-7738, 2007.

[17] J. Takadoum et al., Nanomatériaux, traitement et fonctionnalisation des surfaces, Lavoisier, 2008.

[18] J. Lintymer, N. Martin, J. M. Chappé, P. Delobelle, and J. Takadoum, "Influence of zigzag microstructure on mechanical and electrical properties of chromium multilayered thin films," Surface \& Coatings Technology, vol. 180-181, pp. 26-32, 2004.

[19] J. Lintymer, J. Gavoille, N. Martin, and J. Takadoum, "Glancing angle deposition to modify microstructure and properties of sputter deposited chromium thin films," Surface \& Coatings Technology, vol. 174-175, pp. 316-323, 2003.

[20] K. Robbie, M. J. Brett, and A. Lakhtakia, "Chiral sculptured thin films," Nature, vol. 384, no. 6610, p. 616, 1996.

[21] J. Rathouský, V. Kalousek, V. Yarovyi, M. Wark, and J. Jirkovský, "A low-cost procedure for the preparation of mesoporous layers of $\mathrm{TiO}_{2}$ efficient in the environmental clean-up," Journal of Photochemistry and Photobiology A, vol. 216, no. 2-4, pp. 126-132, 2010.

[22] P. Hájková, P. Špatenka, J. Krumeich et al., "Antibacterial effect of silver modified $\mathrm{TiO}_{2} / \mathrm{PECVD}$ films," European Physical Journal D, vol. 54, no. 2, pp. 189-193, 2009.

[23] J. A. Thornton, " Influence of apparatus geometry and deposition conditions on the structure and topography of thick sputtered coatings," Journal of Vacuum Science \& Technology, vol. 11, no. 4, pp. 666-670, 1974. 
[24] S. C. Jung, "Photocatalytic activities and specific surface area of $\mathrm{TiO}_{2}$ films prepared by CVD and sol-gel method," Korean Journal of Chemical Engineering, vol. 25, no. 2, pp. 364-367, 2008.

[25] P. Hajkova, P. Spatenka, J. Horsky, I. Horska, and A. Kolouch, "Photocatalytic effect of $\mathrm{TiO}_{2}$ films on viruses and bacteria," Plasma Processes and Polymers, vol. 4, no. 1, pp. S397-S401, 2007.

[26] J. Zíta, J. Krýsa, U. Černigoj, U. L. Štangar, J. Jirkovský, and J. Rathouský, "Photocatalytic properties of different $\mathrm{TiO}_{2}$ thin films of various porosity and titania loading," Catalysis Today, vol. 161, no. 1, pp. 29-34, 2011.

[27] I. Paramasivam, J. M. Macak, and P. Schmuki, "Photocatalytic activity of $\mathrm{TiO}_{2}$ nanotube layers loaded with $\mathrm{Ag}$ and $\mathrm{Au}$ nanoparticles," Electrochemistry Communications, vol. 10, no. 1, pp. 71-75, 2008.

[28] T. Watanabe, A. Nakajima, R. Wang et al., "Photocatalytic activity and photoinduced hydrophilicity of titanium dioxide coated glass," Thin Solid Films, vol. 351, no. 1-2, pp. 260-263, 1999.

[29] T. S. Yang, C. B. Shiu, and M. S. Wong, "Structure and hydrophilicity of titanium oxide films prepared by electron beam evaporation," Surface Science, vol. 548, no. 1-3, pp. 7582, 2004.

[30] T. Miyagi, M. Kamei, T. Mitsuhashi, T. Ishigaki, and A. Yamazaki, "Charge separation at the rutile/anatase interface: a dominant factor of photocatalytic activity," Chemical Physics Letters, vol. 390, no. 4-6, pp. 399-402, 2004. 


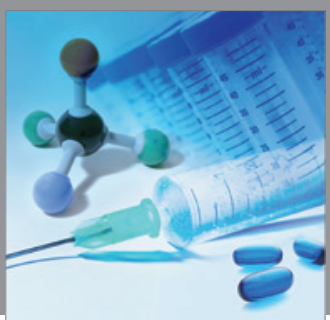

International Journal of

Medicinal Chemistry

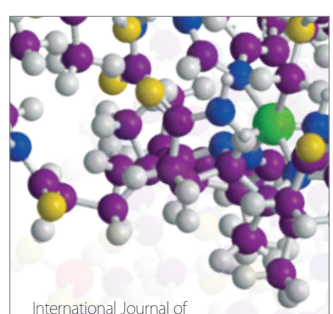

Carbohydrate Chemistry

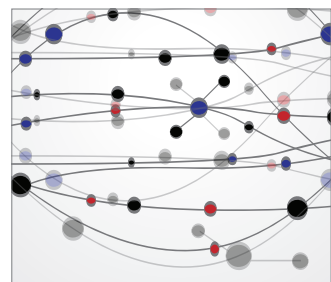

The Scientific World Journal
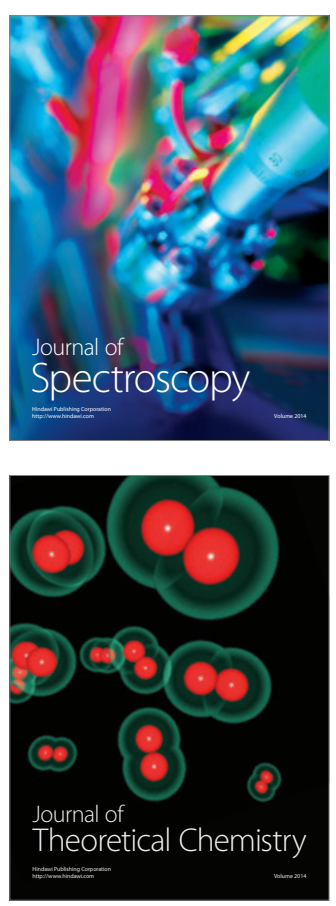
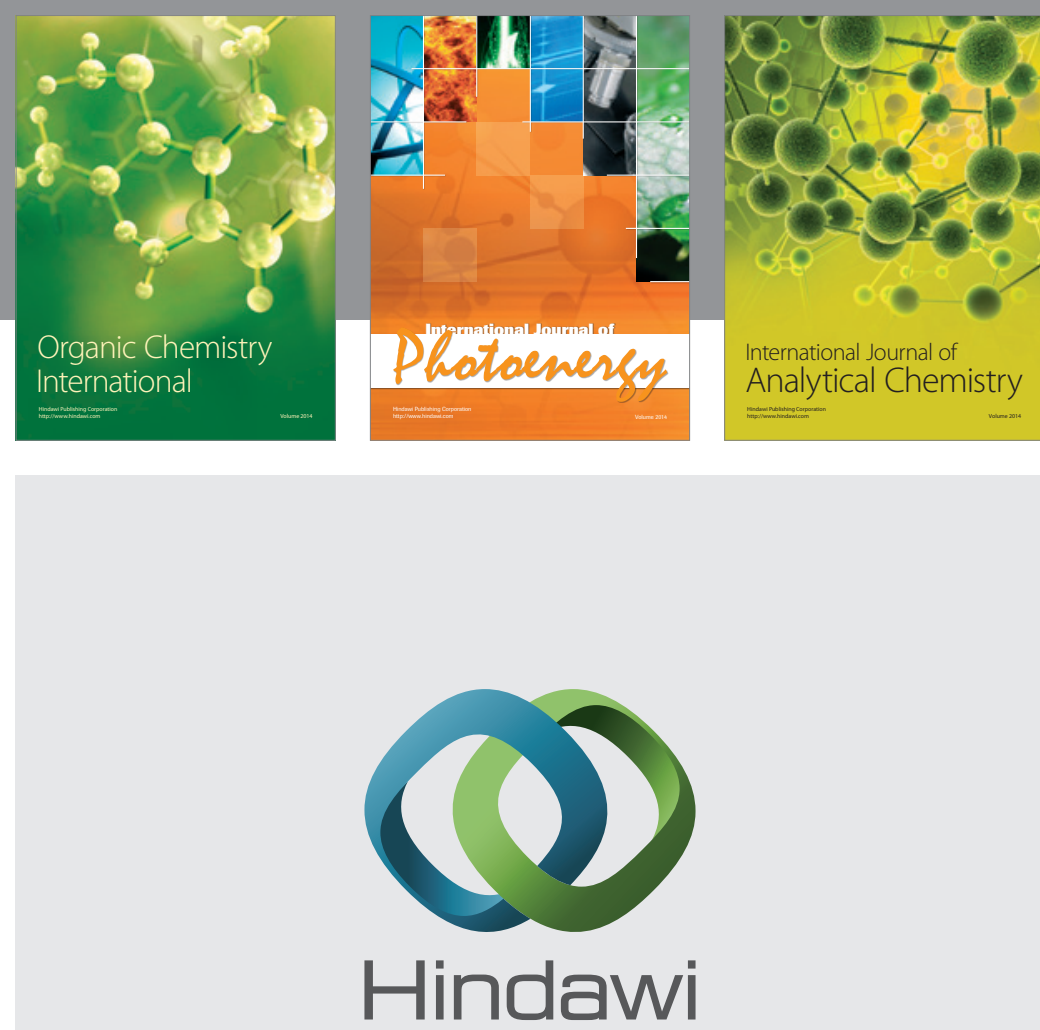

Submit your manuscripts at

http://www.hindawi.com
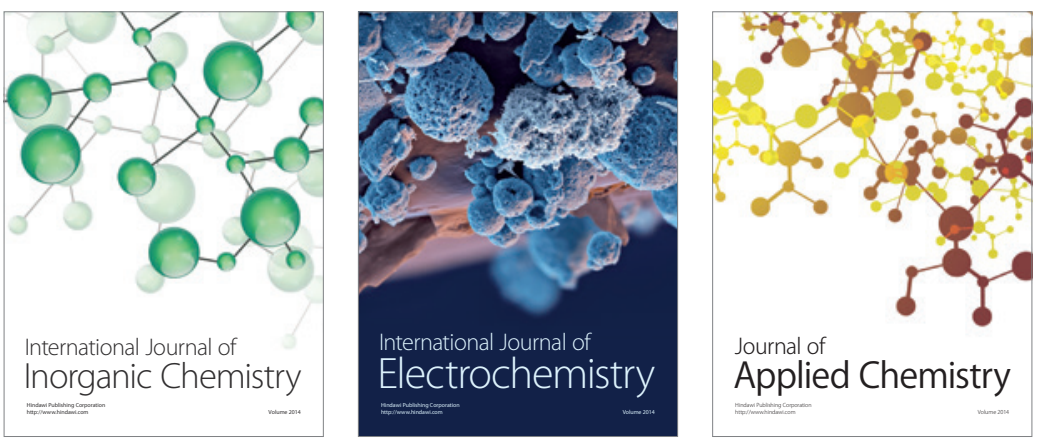

Journal of

Applied Chemistry
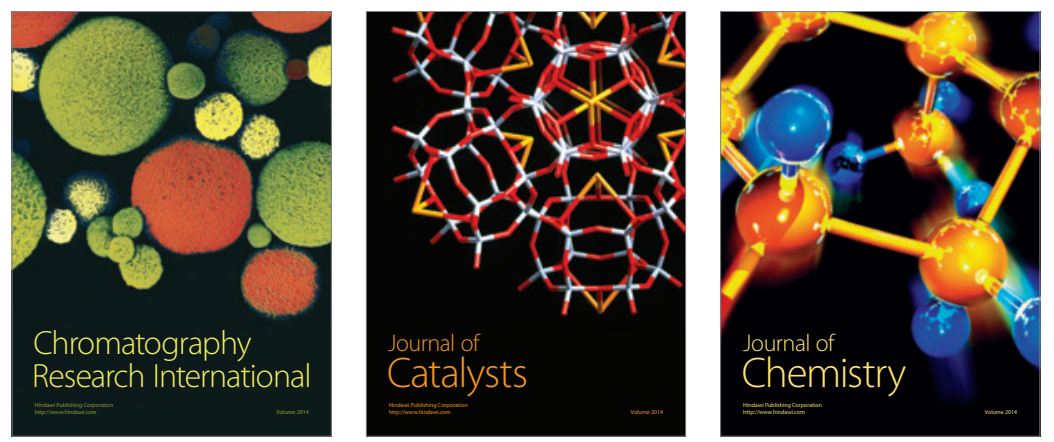
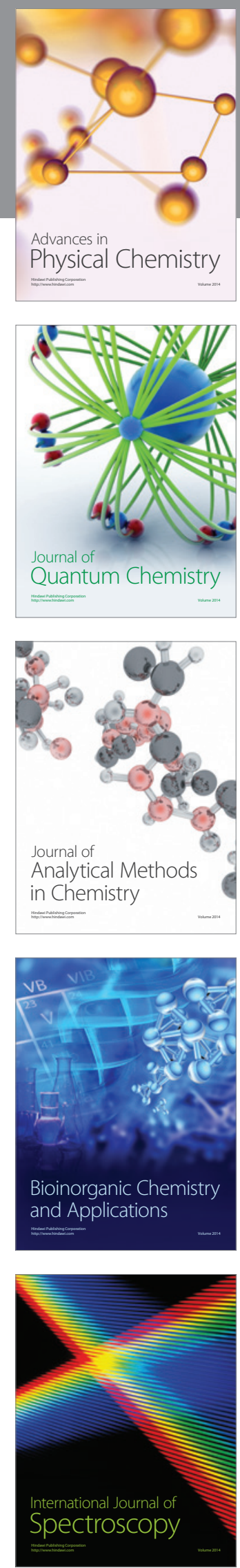